\title{
Sciendo
}

Administration, vol. 68, no. 4 (2020), pp. 73-96

doi: 10.2478/admin-2020-0025

\section{Building transformative capability through civil service reform}

\author{
Peter Thomas \\ Senior Fellow, Institute for Government, UK
}

\begin{abstract}
This article explores the importance of capability building to the success of public service reforms. It draws on the neglected literature on capability to explore how capability is a product (or not) of the interaction between the skills, experience and methods of an individual - and the culture, structures, processes of the organisation they work in. The analysis identifies four key features of successful capability-building reforms in the UK, which are also found in the early successes of the Goal Programme for Public Service Reform and Innovation: an iterative and permissive approach to project identification and scoping; projects on high-priority, cross-cutting outcomes that demand new ways of working; projects that are connected with conducive elements of the organisational and leadership context; projects that are designed to create or adapt 'enabling routines' which civil servants 'learn by doing'. Such reforms have acted as capability factories. And as the early adopters of new routines rise through the organisation and take on new roles, they become advocates and teachers of the routines and practice they have acquired. This is how organisations learn and build the capability they need to succeed.
\end{abstract}

Keywords: Capability, reform, transformation, public

\section{Introduction}

This article explores the importance of capability to the success of reforms by: 
- considering what capability is and how it is built;

- picking out some of the key features of successful capability building that lie behind the most impactful civil service reforms in the UK over the last forty years;

- reflecting on how far those features are reflected in the evaluation of the Goal Programme for Public Service Reform and Innovation, an Atlantic Philanthropies funded project to encourage systemic change in public services in Ireland in order to improve outcomes for people using public services.

The author has worked at the heart of key UK civil service reforms: as founding member and then head of the Prime Minister's Delivery Unit (PMDU) and as leader of the Capability Reviews programme. He led the Institute for Government's work on capability, the alchemy of successful civil service reform, and leadership of change in the civil service. He was adviser to one of the Goal Programme's projects and part of the Institute of Public Administration (IPA) team which evaluated the progress of the Goal Programme. He is an associate of the Centre for Effective Services (CES) in Dublin and a senior fellow at the Institute for Government.

\section{What is capability and how is it built?}

Capability is not an abstract concept. It only has meaning in relation to the priorities and purpose of the organisation. I prefer to use the term capability to capacity because the latter is too often misused by practitioners as they have conversations about quantity rather than quality, and propose solutions like 'we need more of these skills, or these sorts of people'. In so doing they completely miss the point about how you create capability in organisations.

Too often civil service reformers talk about capability and skills interchangeably. They have tended to focus on attracting new staff from outside the civil service to bring in the 'missing' skills. These efforts are often thwarted when those people struggle once inside the civil service. The way things are done in the civil service decision-making, accountability, processes and culture - impedes their effectiveness.

Capability $=$ skills + context. To paraphrase a much-loved management cliché: context would appear to eat skills for breakfast. 


\section{Building capability: Learning and embedding 'enabling routines'}

The relatively neglected literature on capability building and organisational learning (Levitt \& March, 1988; Tranfield et al., 2000) has coined the term 'organisational routines' to explain how capability is developed and retained. In other words:

repetitive patterns of activity that constitute the ways in which the organisation has learned to co-ordinate its activities. (Tranfield et al., 2000)

Behaviours are based on routines; organizations learn these routines by encoding inferences from history into routines that guide behaviour - includes structure of beliefs, culture, codes that reinforce those routines. They are capable of surviving considerable turnover in individual actors. (Levitt \& March, 1988)

Tranfield et al. (2000, pp. 253-4) distinguish 'standard routines' which enable the organisation to become a more effective or efficient machine through one-off improvements from 'enabling routines'. And there are 'defensive routines' which perpetuate the status quo:

Standard routines 'are the most common type. They pull production or service through the enterprise and comprise the most tangible and observable ways in which organisations work on a day-to-day basis.'

Defensive routines 'are routines used by organisational members to avoid embarrassment or threat... that might result from change. They usually involve diverting attention or blame away from the person(s) under scrutiny to other parts of the organisation but in ways that are not always obvious. Defensive routines can be both conscious and unconscious. Whilst such routines can be functional in that they prevent open conflict and preserve the status quo, they are at the same time dysfunctional, as they mitigate against organisational learning and regeneration.'

It is 'enabling' routines which create the dynamic capabilities of an organisation that are most important for designers of civil service reform. These include both 'improvement routines' and 'transformational routines' (Tranfield et al., 2000, p. 254): 
Improvement routines... allow firms to do what they do better and often comprise the basis of continuous improvement initiatives.

Transformational routines... are the least common sets of routines but potentially the most valuable in that they have the potential to enable firms to do something radically different from what they are used to doing.

How do organisations acquire new routines?

Pisano (2002) looked at some of the ways in which biopharmaceuticals create organisational knowledge and capabilities. He identified 'learning by doing' and 'learning before doing' (modelling and simulation) as the main ways in which organisations learn, with the former usually being more important:

'The seeds of today's capabilities are sown in yesterday's experience', but not all experience produces learning: some experience is more useful than others, and organizational routines play a big part in assimilating that experience into knowledge.

There is a substantial body of research into the effectiveness of stateaid and donor-funded projects seeking to build the capability of government and their civil services in developing countries. There is significant convergence on the view that the more effective interventions are characterised as 'problem driven, iterative adaptation' and 'politically smart, locally led' (see, for example, Andrews et al., 2012; Booth \& Unsworth, 2014; McCourt, 2014; Rocha Menocal, 2014).

These researchers may use different language from the 'routines' of the capability literature but they are describing the same process. Andrews et al. (2012, pp. 10, 14) coin the phrase 'bricolage':

[the] process by which internal agents 'make do' with resources at hand to foster new (or 'hybrid') structures and mechanisms.

They propose that capability-building interventions should:

[involve] active, ongoing and experiential learning and the iterative feedback of lessons into new solutions. 
This kind of experimentation... is about trying a real intervention in a real context, allowing on-the-ground realities to shape content in the process. This is also not about proving that specific ideas or mechanisms universally 'work' or do not work. Rather, it is about allowing a process to emerge through which attributes from various ideas can coalesce into new hybrids. This requires seeing lessons learned about potential combinations as the key emerging result. The necessary experimentation processes require mechanisms that capture lessons and ensure these are used to inform future activities.

If capability $=$ skills + context, what are some of the critical features of context? And if they are not present, how do you create them? It is the organisation's dynamic capabilities which provide the most conducive context to building enabling routines - which in turn ensure a smart, continuously learning organisation which can 'keep the change changing'.

In 2007 the Sunningdale Institute (SI) carried out an evaluation of the UK cabinet secretary's (Lord O'Donnell) flagship reform - the UK Capability Reviews programme. The SI was a virtual academy of thought leaders from the UK and elsewhere, primarily in management, organisation and governance. It was launched in November 2005 and regrettably wound up in 2012 when the Institute for Government was created. The institute's mission was to offer 'practical wisdom' to government to help improve service and outcomes for the public. Fellows offered new ideas and insights, undertook high-level interventions and together reflected on the learning which comes from that experience.

In its 2007 report (pp. 10-12) the SI set out some specific characteristics required for a more dynamically capable civil service:

- socially distributed leadership: i.e. everyone in the organisation has a leadership role. In this type of context, it is accepted that everyone has two jobs: 'their day job' and 'improving their day job'.

- a 'learning to learn' culture: within which change is continuous rather than spasmodic and there is a commitment to learn from anyone who does something better inside or outside the organisation.

- effective cross-department working: because the main focus would be on continuously improving the response to external challenges, opportunities and stakeholders, rather than focusing on the 
convenience of providers or the maintenance of existing procedures.

An enabling condition for dynamic capabilities is an open, honest culture characterised by mutual respect and a commitment to keeping promises. There should be no gap between what leaders (at all levels) say and what they do.

One feature of such a culture is open dialogue that includes frank challenges to existing ways of working. This includes (Shreyögg \& Kliesch-Eberl, 2007):

- use of outside challenge;

- culture of positive criticism;

- acceptance of dissent;

- strong customer orientation.

Rather than expect rapid, system-wide development of dynamic capabilities through some grand transformation plan, the SI proposed that civil service leaders should pick a small number of high-priority issues to act as trailblazers for the wider civil service. Those would be used to equip civil servants to adapt, practise and deploy some simple but transformative routines. Developing and supporting the dissemination of these routines would be a key role for the corporate leadership of the civil service and the central teams who support them.

The design and leadership support of these trailblazers would be the engine room of capability building. The trailblazers would:

- specify a particular challenge that is a high priority and has strong ownership from senior leaders - whether politicians or officials.

- establish a way of working that would blend outward-looking, structured problem-solving tools together with excellent collaborative working methods.

- create teams drawn from different parts of the service and beyond to work together to create a shared understanding of the problem, and to study and learn widely from (either in-house or other 'live' organisations, or from the literature). The diversity and lack of hierarchy of the team are critical to its effectiveness.

- provide support and coaching to the project team to help them learn and use these new routines - which must be embedded in how they work on the trailblazers.

- make time to reflect and adapt the trailblazer approach once sufficient progress has been made in the beacon areas. 
- celebrate and disseminate. The approach would be rolled out more widely, led by those who worked on trailblazers, who overtime form a large group of advocates, champions and teachers of these new transformative routines.

- reinforce the use and value of these routines by including them in the curriculum for staff and leadership development.

The development of dynamic capabilities requires an uncomfortable 'lurch into the unknown' for many senior leaders.

It requires them to open up policymaking by engaging others across government and beyond in scoping and shaping the policy from the earliest stages. In turn this requires more permissive leaders who let go of their desire to control 'the right answer'. Such leaders are comfortable to set broad direction and clarify political imperatives but give maximum space to those working on the policy to explore a range of options and approaches. This may require an iterative approach to framing the challenge or problem and identifying potential solutions.

The mindset of UK policymakers needs to avoid the trap of thinking they know best and instead look more outside the civil service to front-line staff, citizens and practice in other jurisdictions. Leaders need to acknowledge that the civil service does not have a monopoly of insight and expertise.

This approach demands more permissive and supportive management of teams. This means freeing up their best staff to work across departmental boundaries, sometimes reporting to other leaders in other departments or organisations.

Finally, they must prioritise time for reflection, learning and adjustment. This means being prepared to invite different and sometimes critical voices into the process of reflection; to accept challenge; and to ask questions and listen with humility and an eagerness to learn.

Unfortunately, since around 2016, after several decades of progress, the UK government would seem to be lurching rapidly in the opposite direction to that of building dynamic capabilities.

\section{What can be learned from civil service reform in the UK?}

\section{A chaotic agglomeration of reforms}

Most UK reforms over the last forty years address one or more of six themes identified by Panchamia \& Thomas (2014) as a feature of recent civil service reforms (Figure 1). Capability has been an explicit or implicit requirement of them all to differing extents. 
Figure 1: The patterns of UK government reform

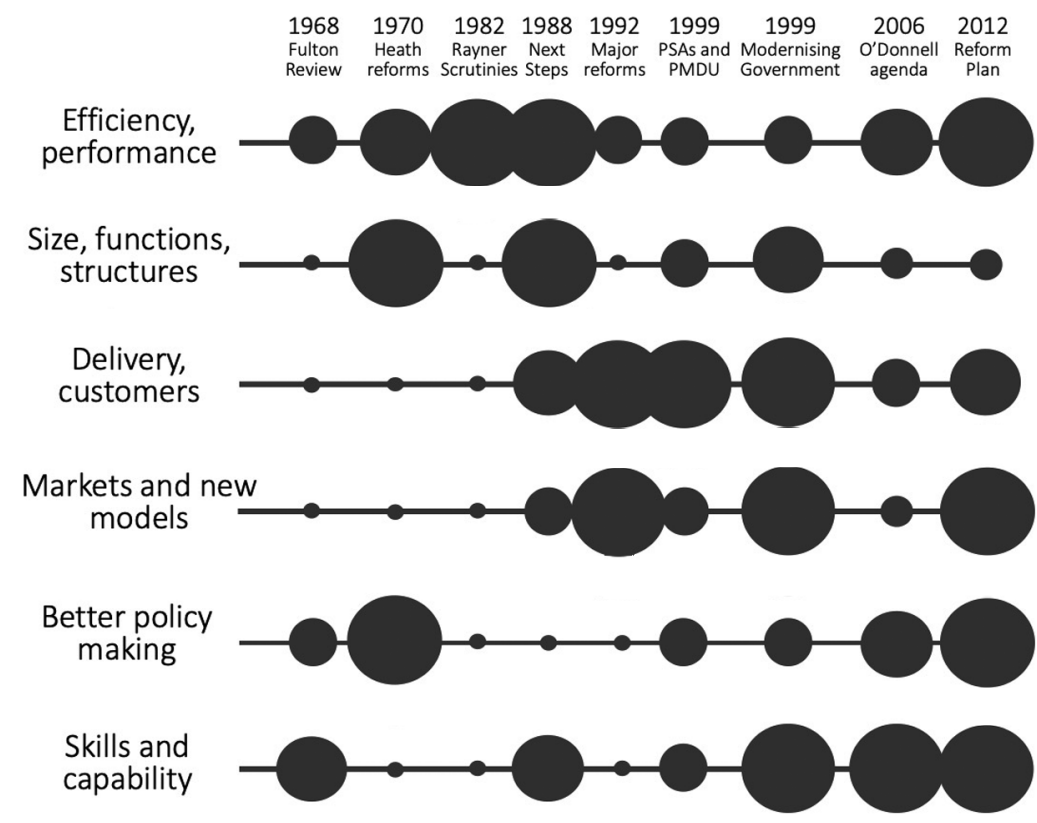

Note: The themes are consistent across successive waves of reform over forty years, but the focus shifts significantly from wave to wave. The bigger the circle, the greater the emphasis on that theme in the particular reform pulse. Source: Analysis by Peter Thomas.

The patterns of action and progress within these reform themes are not smooth - instead they tell a story of an erratic, episodic and incoherent sequence of reform attempts, often unconnected to a broader vision about how the civil service should operate. As Pollitt \& Bouckaert (2011, p. 34) comment:

Typically there is no single design or designer. There are just lots of localised attempts at partial design cutting across one another... It is easy to exaggerate the degree of intentionality in many reforms.

Within this messy picture, a string of key reforms has transformed the capability and culture of the civil service in a way that has survived the rise and fall of the leaders, teams, structures and programmes of successive reforms. 
The reforms that were central to this transformation include:

- 1980-1986: Rayner Scrutinies - a new way of working across departments to identify efficiencies;

- 1987-1995: Next Steps reform;

- 1991-1997: Citizen's Charter;

- 1999-2003: Bringing in and Bringing on Talent;

- 1999-2020: Valuing and building 'the professions' - legal, HR, IT, project and programme management, finance, procurement;

- 2001-2010: Prime Minister's Delivery Unit;

- 2005-2012: Capability Reviews.

The key aspects of the resulting transformation include many of the elements of dynamic capability described by the SI (2007):

- a stronger sense of personal responsibility and accountability for delivery - whether of policies, projects, programmes or services;

- the use of objectives, performance indicators and measurement to make progress transparent and provide comparisons or challenge;

- more open competition for senior roles and greater diversity of the civil service;

- greater value placed on the quality of leadership and management;

- a more outward-facing organisation connected to other organisations, perspectives and ways of thinking to inform the policydevelopment process;

- learning and adopting new ways of working which outlasted the reform that introduced them.

\section{Three key UK reforms that transformed capability}

The story of three of these reforms outlines how they transformed capability by changing who UK civil servants are, how they see their role and accountability, how they work and consequently how they think.

The reforms made these changes by introducing new routines, new accountabilities and new ways of working - which in turn changed incentives, rewards, behaviours and attitudes. These changes have all long outlasted the initial reform or central teams supporting them, and they have continued to evolve in the hands of new generations of civil service leaders. 


\section{Next Steps ${ }^{1}$}

The Next Steps initiative (1987-1995) is seen as one of the two or three key reform moments in the development of the contemporary UK civil service. It was a direct consequence of the 'lasting reforms' agenda of Sir Derek (later Lord) Rayner (Margaret Thatcher's efficiency adviser) in the early 1980s.

It began ambitiously, hiving off between 75 and 95 per cent of the civil service to arm's-length agencies within five years, and immediately had a huge impact. It fundamentally changed the shape and mindset of the civil service. It introduced some 'hard' changes in the operating model of the civil service. Greater freedom from the centre contributed to a greater focus on customers and led to tangible improvements in front-line public services. It also fundamentally changed the agenda on staffing and appointments. First, it gave a push to openness and the idea that people other than civil servants could effectively run certain delivery functions. This led to greater acceptance of open competition and the value of bringing people in from the private sector.

Ceding the organisations to a different sort of person... those people were very much more public and they had a more direct relationship with Parliament. (Panchamia \& Thomas, 2014, p. 38)

There is evidence that suggests greater freedom from the centre contributed to a greater focus on customers and led to tangible improvements in front-line public services (HM Treasury \& Prime Minister's Office of Public Services Reform, 2002):

- Companies House reduced the amount of time taken to process documents from twenty-five days to four (by 2002). Its unit costs fell by 18 per cent over the three years to 2001 .

1 The summary of each of the reforms draws heavily on a fuller case study produced by this author whilst at the Institute for Government. The full case studies can be found at: Next Steps: https://www.instituteforgovernment.org.uk/sites/default/files/case $\% 20$ study\%20next\%20steps.pdf

BILBO: https://www.instituteforgovernment.org.uk/sites/default/files/case \%20study\% 20bilbo.pdf

PSAs and PMDU: https://www.instituteforgovernment.org.uk/sites/default/files/case\% 20 study\%20psas.pdf 
- By 2002 HM Land Registry had reduced its fees by 40 per cent and achieved a 40 per cent improvement in efficiency since becoming an agency in 1990.

- The UK Passport Agency reduced the amount of time taken to process a passport from ninety-five days to ten days (by 2002).

The initiative changed the way policymakers in the remainder of the civil service thought about policy.

[Before Next Steps] policy makers made policy but didn't influence or help those trying to run the operations... [it was] unrealistic policy - being made without any sense of reality. Then after Next Steps... people talked about the importance of understanding the reality... [there was] much more movement of fast streamers to spend time in local offices trying to understand reality... concepts like customer focus came in and people at more senior levels recognised they had to think about these issues. (Panchamia \& Thomas, 2014, p. 38)

Implementation of the reforms was driven by the newly created Next Steps Unit (NSU). The NSU was seen as a tight ship comprising 'misfits', 'slightly awkward people' and - unusually - a few outsiders, many of whom had a strong understanding of service delivery. Following the lead of the unit head, Sir Peter Kemp, they acted as disruptive mavericks armed with an unwavering commitment to changing things.

The unit developed a clear set of processes to decide when a new agency would be established and what form it should take (later developed into a thirteen-point checklist of essential criteria for an agency). This involved conducting a review of pre-agency functions to assess what was supposed to be delivered; what management structures would make it work better; and whether performance would improve if the function was privatised, abolished or established as an agency. Then, arising from this review, the NSU team would specify the relationship between the parent department and the agency in a carefully crafted, bespoke framework agreement, which set out the objectives, performance targets and resources assigned to each agency. This was drawn up in consultation with the Treasury, and single negotiations would take place on any proposed changes to staff pay and conditions. Finally, each agency was formally launched with a public statement from the relevant minister. 
Next Steps instilled a clearer idea of what officials were supposed to be delivering. The framework agreements were seen as exemplars of setting objectives and resources as well as facilitating measurement of performance. This process encouraged people to look closely at a department and ask what it was there for, laying the foundations for the public service agreements (PSA) agenda, which identified objectives for each department from 1998 (see below).

\section{Bringing in and Bringing on Talent}

Bringing in and Bringing on Talent reform (1999-2003) contributed very significantly to changing the skills, diversity and experience of the senior civil service within only five years. The way it was led and refreshed under successive cabinet secretaries makes it the best (and one of the only) example of sustained corporate leadership by permanent secretaries over the last twenty years.

The primary purpose was 'to strengthen leadership of the civil service across the board' by cultivating talent and building the capability of staff, as well as accessing a wider range of talent from outside. Opening up the civil service to outsiders was seen as very new and risky at the time, given the norm of a 'career for life' in one organisation.

Cabinet Secretary Richard Wilson wanted to give the agenda some structure and push, but understood that it could not be driven by the cabinet secretary alone and had to be 'owned' by permanent secretaries themselves. In April 1999 he created a working group of permanent secretaries and delegated leadership of the group to the permanent secretary at the Home Office, until around 2002.

The working group developed a vision of what 'success' would look like in 2005 and worked backwards to operationalise how exactly to get there. In this ideal future state, the senior leadership would contain as many women as men, those from an ethnic minority or disabled background, those who had taken a career break, those who had worked in local government, the voluntary or private sector, and those who had a scientific or technological background. Also envisioned was a 'failure' state: here, the senior leadership would still be largely male, from the same backgrounds and almost entirely white.

They developed a strategic plan for getting to the desired future. This consisted of five objectives:

1. provide the individuals for strategic leadership of the service with relevant experience; 
2. create a broader-based, more professional civil service;

3. spot and develop talent by providing opportunities for people to gain experience in more than one department or outside Whitehall;

4. recruit in mid-career to fill specific posts needing outside experience, such as service delivery;

5. attract a wider, more diverse group at entry level.

They deliberately avoided the imposition of specific rules, targets and progress chasing (although they did track progress against objectives), and instead gave departments a menu of options. The rationale was that if departments did 'at least some of them, the whole thing would move in the right direction'.

More generally, the role of the centre was limited to connecting people and sharing best practice between departments in order to accelerate trends already under way.

Subtle incentives demonstrated the importance of outside experience. People started to see that those who had experience from outside were promoted, while those who didn't were prevented from reaching the senior positions that were once seen to be natural successors. This had a powerful effect and compelled people to get on board with the agenda of promoting secondments and interchange.

Within a couple of years, there were a number of visible 'quick wins'. By 2002 two-thirds of senior vacancies were filled from outside, an increase of 88 per cent from 2000.

Within just a few years the diversity of the senior civil service was significantly changed, and the actions became embedded. Although the reform project team was wound up swiftly, the embedded reform actions continued to be pursued and were subsumed within new agendas. All the key themes were an integral part of the Civil Service Capability Plan, published in 2012.

\section{Public service agreements and the Prime Minister's Delivery Unit}

The introduction of PSAs was unexpected and unplanned - proposed by the Chancellor's special adviser just days before the 1998 spending review was announced. An initial set of 600 rapidly assembled PSAs matured and then burst into life when Tony Blair gave Michael Barber his 'instruction to deliver' in 2001. The PMDU (2001-2010) became the most notable component of the reform and, together with the later evolution of the PSA regime, is now the UK civil service's best-selling reform export. 
Departments remained responsible for achieving their PSA targets, but PMDU was seen to play a crucial support and challenge function through the deployment of a range of tools and processes. It adopted an evidence-based approach to identifying and tackling barriers to delivery. It used the red-amber-green traffic-light rating system to assess the progress departments had made. The first league table was produced four months into PMDU's life and was intended to 'send shockwaves through the system'. After this, the ratings featured regularly in the six-monthly delivery reports.

When delivery was off track, PMDU worked with departments to identify and tackle specific delivery challenges through the priority review, which was developed off the back of PMDU's success on the 'street crime' target. The priority review was a short, intense period of work (usually six weeks) intended to identify barriers to delivery and develop solutions and recommendations. These reviews culminated in a prioritised action plan. PMDU would then offer departments a dedicated resource in that area to help think through some of the issues.

The PSA framework was a flexible system that evolved. The targets gradually became smarter in response to challenges, difficulties and unintended consequences. In particular, there was, over time, an explicit limit on target numbers and a shift from inputs to outputs and sometimes even outcomes.

The performance management machinery of PSAs and PMDU is widely seen as 'a good thing' among officials and ministers who worked with it. It offered a framework for setting long-term priorities and aligning organisational resources behind them. As one official explained, it was clear that the government cared about certain issues, such as health waiting times or school standards, which meant that, even if ministers came and went, the priorities remained. The PSA machinery provided a 'guiding star to the policy direction of the whole government'. As a result, in those areas where PMDU focused, the machinery led to a strong stock of departmental delivery success stories.

More fundamentally, the approach is seen to have made civil servants and ministers feel directly accountable for delivery. Permanent secretaries began to accept that delivery was a major part of their day job - whether it was reducing crime through the Home Office or raising educational standards through the Department for Education. This would have been unthinkable in the 1970s and 1980s, when most officials thought they were supposed to focus only on policy formulation and legislation. 
Particularly for departments working with PMDU, the whole process embedded a set of positive routines. Some departments put PSAs at the core of their board reporting system, which increasingly focused on the delivery of long-term outcomes regardless of political cycles and day-to-day urgencies.

After coming to power in May 2010, the coalition government immediately abolished the PSA/PMDU machinery and replaced it with structural reform plans. This reflected the bizarre and unsustainable position of No. 10 that government cannot commit to outcomes that it cannot wholly control. The resulting hands-off approach to delivery by David Cameron and No. 10 was quickly seen by many inside and outside government as a big mistake. Within two years of abolition the approach and tools of PMDU re-emerged in the guise of the revamped Implementation Unit, which survives to this day.

Ex-PMDU officials and many of those who worked with the approach in departments still use the tools and processes. The Implementation Unit in the Cabinet Office uses tools from the PMDU era as an integral part of how it works. The conduct of, and input into, today's stocktakes on areas of prime-ministerial interest would be recognisable to officials and ministers from that era. In 2020 the exhead of that implementation unit (Simon Case) was appointed cabinet secretary.

\section{The key features of these reforms that explain a sustained change in capability}

Two features stand out as explaining much of the impact these reforms had on civil service capability.

\section{Taking time to create engagement and a shared sense of purpose}

Building a coalition of political and/or official leaders around a reform is a staple of change advice. In the reforms summarised above reform leaders worked hard to create the necessary connections, support and relationships to get the reform off the ground. For example, in Next Steps, substantial time and energy was invested in negotiating with the Treasury to secure its support for the agenda. This was critical to getting the reform off the ground. In Capability Reviews, engagement was designed into the process from the outset and senior officials were actively involved in co-producing the method for conducting reviews. This ensured that there was broad support for the aims and approach of the reviews. 
An enduring weakness of corporate leadership in the civil service is the lack of time spent really nailing down what reforms are trying to achieve. At the early stages of every reform initiative, time needs to be spent defining the end state that the organisation is seeking to achieve and the gap between this end state and the current situation. This demands an open-minded, engaging and collaborative effort to rescope and re-frame the issues in a way that engages colleagues, staff and ministers - and is seen to be highly relevant to local priorities and problems.

At this early stage it is more helpful to establish a good sense of the desired direction of travel rather than to encourage or reinforce expectations of the specific form and outputs of a potential project. Otherwise, the depressing default of the centre to impose an unsuitable solution to an uninterested or sceptical civil service will guarantee that once compulsion ends, normal service is resumed.

\section{Designing the reform to teach and spread new 'enabling' routines}

Too much reform and policymaking is distinguished by the lack of thought about the theory of change and the failure to invest enough effort and time into the detailed design of changes and their implementation. But each of the key reforms above consciously constructed the resources, people, structures, procedures and practices needed to drive changes and build relevant capabilities.

Small, dedicated central teams supporting reforms often played the key role in co-creating new routines and supporting colleagues as they applied them. These teams were successful when they worked in a highly collaborative and iterative way. Their way of working was a crucial part of the design of the change.

PMDU adapted and developed a whole host of tools and processes such as the stocktake process, trajectories, priority reviews and delivery reports, which maintained a constant pressure on senior officials to improve delivery.

Because the PMDU staffing model relied on secondments and coopted departmental colleagues onto specific pieces of work, fifteen years later there are as many as 5,000 civil servants who worked in and with the Delivery Unit and the Implementation Unit that followed it. They learned new routines and practices, which they applied and embedded in their departments as an integral part of both policymaking and performance management. Many of those alumni have become director generals and permanent secretaries, thus ensuring strong leadership support for these routines within their respective departments and agencies. 


\section{The Goal Programme and capability building}

\section{The Goal Programme and early signs of impact}

In 2016 the Goal Programme for Public Service Reform and Innovation (funded by Atlantic Philanthropies) invested $£ 10$ million in nine strategic sectoral reform exemplar projects in Ireland and Northern Ireland. It sought to encourage systemic change in public services in order to improve outcomes for people using public services. The CES delivered the programme in partnership with seven government departments in Ireland and Northern Ireland. The CES is an independent, non-profit, all-island organisation set up in 2008 that aims to connect policy, research and practice, in order to help agencies and government bodies design and plan services in health, social care, education and services for young people.

An evaluation led by the IPA was published in 2019 (Boyle et al., 2019):

There is now a group of public servants thinking and acting differently and working in new ways. This would not have happened without their participation in the Goal Programme.

This conclusion from the IPA's evaluation goes to the heart of the characteristics of successful civil service reform. The Goal Programme sought to build capability by providing external support to a number of exemplar projects.

[Goal] should focus on a number of existing large-scale sectoral reform programmes which are 'ready to go' and use these as a platform for embedding new ways of working in the public and civil service. (Boyle, 2018, p. 3)

The nine Goal Programme projects were:

1. Developing Evidence and Knowledge Management (Department of Health, Ireland);

2. Youth Mental Health and Wellbeing Pathfinder project (Department of Health, Ireland);

3. Building Collaborative Working Practices (Department of Education and Skills, Ireland);

4. Using Data to Inform Policy (Department of Education and Skills, Ireland); 
Figure 2: Revised logic model for the Goal Programme

\section{Revised Logic Model - Short-term Outcomes}

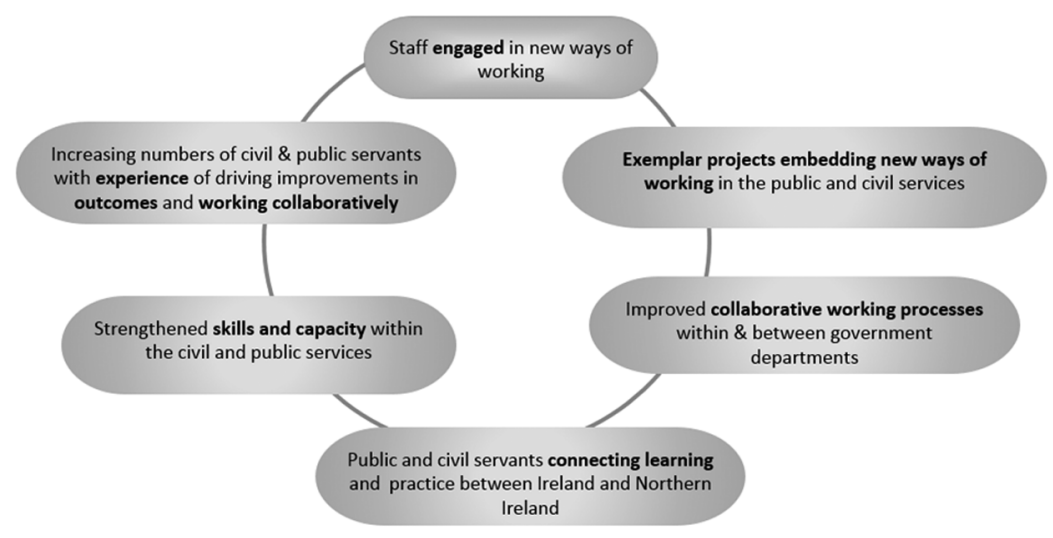

Source: Boyle et al. (2019, p. 18).

5. Reform of Youth Funding Schemes (Department of Children and Youth Affairs, Ireland);

6. Evaluation Training for Civil Servants (Department of Children and Youth Affairs, Ireland);

7. Leadership Development programme (The Executive Office, Northern Ireland);

8. Children and Young People's Strategies (Departments of Education and Health, Northern Ireland);

9. Embedding Innovation (Department of Finance, Northern Ireland).

The evaluation was carried out in 2019. Whilst for many projects it was still quite early to be able to judge any lasting impacts and benefits, the authors provided some initial findings (Boyle et al., 2019, pp. 224-30). They concluded that the Goal Programme has been successful in helping staff engage in new ways of working. And there have been signs of participants repeating and extending the use of techniques into their teams and networks: 
- Greater collaboration and improved engagement were seen to have been achieved by several projects.

- There was evidence of new routines and different ways of thinking being replicated or extended.

- There were signs of lasting change in how leaders think and behave - in particular the value of focusing on outcomes that require collaboration.

\section{What were some key factors that explain success?}

Through my role directly advising one project (the Youth Mental Health and Wellbeing Pathfinder project in Ireland) and later the chance to observe two other projects (the Leadership Development programme, and the Children and Young People's Strategies - both in Northern Ireland), and as part of the team that evaluated the overall Goal Programme, I could explore the extent to which these three projects appear to have produced a lasting change in how some civil servants think and work.

Four factors in their success stand out:

\section{An iterative and permissive approach to project identification and scoping} There was a pragmatic, iterative and adaptive approach to developing these projects in particular, which allowed for engagement, co-design and the handling of significant changes in the context for specific projects.

These three projects were not off the shelf and ready to go or just needing some additional capacity. Instead they were possibilities which needed scoping and co-design with external support. As a result of the process of development and iteration they all had strong senior support - and a high degree of ownership and commitment by the project teams.

The evaluation considered this flexibility and pragmatism to be fundamental to later success (Boyle et al., 2019, p. 43).

You have to start where people are at... actually for them to get their heads around any kind of reform and innovation, that was already a leap because they were trying to keep the show on the road. (Boyle, 2018, p. 2)

A Goal Programme approach is particularly useful when there is scope to shape and design the project and use external expertise to plug gaps rather than as an extra pair of hands. In other words, 
this type of approach works best when the desired outcomes are reasonably clear but where the means of getting there need exploration and clarification. (Boyle et al., 2019, p. 11)

\section{Projects on high-priority, cross-cutting outcomes that demand new ways of working}

Projects were sought that focused on a real issue of concern to the public, with cross-organisational boundaries, or ones that address serious capacity (Boyle et al., 2019, p. 46). And whilst the Leadership Development programme was less obviously in this category, it had a very strong focus on cross-cutting outcomes, which in turn connected to strong ownership of the paused programme for government.

When projects focus on the needs of service users and compelling issues of public and policy importance, but where the way to achieve desired outcomes is unclear, they lend themselves to the use of collaboration tools and outcome measures that can be transformative. This can encourage project participants to look across government from the point of view of the user as a driver of change, going outside the boundaries of routine practice. Using collaboration tools and outcome measures can facilitate transformative change. (Boyle et al., 2019, p. 46)

Whilst some other goal projects did not fall into this category, they still made valuable contributions to improving business as usual. However, as such, they offered less insight into the challenge of building transformative capability.

\section{Projects that are connected with conducive elements of the organisational} and leadership context

In Northern Ireland the Leadership Development programme had a strong focus on collaborative leadership, system stewardship and outcome-focused policymaking. Senior leaders across the whole organisation were reflecting on their personal leadership practice and behaviour and how it could better support collaboration to deliver cross-cutting outcomes. The outcome focus reflected the recent development of a draft programme for government which had strong ownership across the senior civil service. The team working on the Children and Young People's Strategies saw these aspects of their context as instrumental to their progress: providing them with priority, authority and leverage for their work. 
In Ireland the wider context was helped by the Civil Service Renewal Plan, launched in 2014. It was an unusually clear and focused reform plan that amongst other things sought to open up recruitment to civil service jobs to those outside the civil service - echoing one of the most impactful UK reforms of the last thirty years. It also created a number of pathfinder projects designed to model new ways of delivering whole-of-government projects. One of those pathfinders was the Youth Mental Health and Wellbeing Pathfinder project. This pathfinder was further helped by having the sponsorship of a deputy secretary general who had been recruited from outside the civil service and was very supportive of the need to do things differently.

\section{Projects that are designed to create or adapt 'enabling routines' which civil servants 'learn by doing'}

Too many projects simply substitute external capacity for the lack of the right internal capability. The most impactful Goal Programme projects I observed made excellent use of external support to facilitate the adoption and adaption of new transformative routines. These routines included open policymaking, structured problem-solving, collaboration and outcome-focused policymaking. Although some of these routines were not new to participants, it was the first time they had explicit permission and support to apply them on high-priority projects - and were easily able to access additional external support.

All three of the projects had significant levels of ongoing external support from the CES and their associates, who helped shape the scope of the project, and then co-designed and co-delivered key elements of the project with the project team.

A critical factor in the choice to apply new tools and methods in one project illustrates the reality of how organisations acquire new routines. The project lead for the Youth Mental Health and Wellbeing Pathfinder project had learned collaborative and structured problemsolving tools through her experience in the Strategy Unit in the UK Cabinet Office and whilst working on secondment with the Institute for Government in London. She saw the opportunity to draw on additional support from the Goal Programme in order to help a pathfinder project learn and use those tools.

The value of experiential learning of new routines as opposed to more conventional policy analysis or classroom training is reflected by comparing the respective impacts and follow-through of the Youth Mental Health and Wellbeing Pathfinder project with the Building Collaborative Working Practices project. The latter carried out much 
valuable work collecting and codifying good practice - and developing Excel-based diagnostic tools. However, at the time of the evaluation there was still not a settled model for how to enable civil servants to acquire and apply the insights that had been developed through the project.

In contrast the team that supported the Youth Mental Health and Wellbeing Pathfinder project designed their project to equip the team to use transformative collaboration and problem-solving tools. After the first pathfinder they commissioned further training for core staff in the facilitation and collaboration tools used in that project. Those staff then immediately applied these methods as they designed and delivered a second pathfinder looking at sexual assault treatment centres - a ministerial priority. They drew on an adviser from the first pathfinder to provide some additional coaching and support at key points in the project and to facilitate reflection and learning sessions for the project team. The pathfinder approach is now at the heart of the practice of the Policy, Strategy and Integration Team in the Department of Health.

Since the first pathfinder a Health Service Executive participant from the project commissioned and led a pathfinder-style project on public health promotion. The Department of Children and Youth Affairs (also a participant in the first pathfinder) has commissioned their own pathfinder-style project on parenting support, drawing heavily on the advice of colleagues in Health, with further support from the CES.

The Department of Health has set up a thriving cross-departmental network for collaboration and facilitation practitioners. Their investment in team training, allied with learning by doing, has enabled them to sustain the approach even without the presence of the original champion and leader of the pathfinder approach.

\section{Conclusions}

The Goal Programme and some key projects within it display many of the characteristics of successful reform efforts which helped transform capability in the UK civil service and elsewhere. The likely impact and sustainability of civil service reform interventions depends upon the extent to which:

1. interventions are designed explicitly so that multiple civil servants experience and learn new, transformative routines which they adopt as their personal practice such that: 
- how they think and how they see their role is different, because they have a better understanding of different perspectives in the systems they work in, and see the impact that government has - they know better what works and what doesn't;

- how they work has changed. They are more open, collaborative - going beyond conventional departmental and service boundaries. They have broadened the methods and techniques they use to collaborate, make policy, solve problems and innovate.

2. there is a sufficiently conducive political and organisational context which:

- defines impact and success of the reform intervention in terms of longer-term priority outcomes that cut across civil service departments, functions and boundaries;

- encourages a diversity of backgrounds and experience amongst civil servants;

- encourages and supports civil servants to learn about what is working and what is not;

- provides an open, honest culture that supports and welcomes constructive challenge with a focus on improvement rather than blame.

The most impactful reforms and exemplar projects in the UK and the whole of Ireland have acted as capability factories. And as the early adopters of new routines rise through the organisation and take on new roles, they become advocates and teachers of the routines and practice they have acquired. This is how organisations learn and build the capability they need to succeed.

\section{Acknowledgement}

Thanks to Marc Kidson (currently Director of System Reform in the New South Wales Department of Education) for his phenomenal research into capability and organisational learning whilst we worked together at the Institute for Government. I have drawn heavily on his unpublished literature reviews and his published discussion paper (Kidson, 2013).

\section{References}

Andrews, M., Pritchett, L., \& Woolcock, M. (2012). Escaping capability traps through problem-driven iterative adaptation (PDIA) [Working paper 299]. Washington, DC: Center for Global Development. 
Booth, D., \& Unsworth, S. (2014). Politically smart, locally led development. Discussion paper. London: Overseas Development Institute.

Boyle, R. (2018). The Goal Programme for Public Service Reform and Innovation. Evaluation vignette 1: Distinctive elements of the Goal Programme. Dublin: Institute of Public Administration.

Boyle, R., O'Riordan, J., Shannon, L., MacCarthaigh, M., \& Thomas, P. (2019). Evaluation of the Goal Programme for Public Service Reform and Innovation. Dublin: Institute of Public Administration.

HM Treasury \& Prime Minister's Office of Public Services Reform. (2002). Better government services: Executive agencies in the 21st century, agency policy review - Report and recommendations. London: HM Treasury.

Kidson, M. (2013). Civil service capabilities: A discussion paper. London: Institute for Government.

Levitt, B., \& March, J. G. (1988). Organizational learning. Annual Review of Sociology, 14, 319-40.

McCourt, W. (2014). Public service reform. GSDRC professional development reading pack no. 1. Birmingham: University of Birmingham.

Panchamia, N., \& Thomas, P. (2014). Civil service reform in the real world. Patterns of success in UK civil service reform. London: Institute for Government.

Pisano, G. P. (2002). In search of dynamic capabilities: The origins of R\&D competence in biopharmaceuticals. In G. Dosi, R. R. Nelson \& S. G. Winter, The nature and dynamics of organizational capabilities. Oxford: Oxford University Press.

Pollitt, C., \& Bouckaert, G. (2011). Public management reform: A comparative analysis. Oxford: Oxford University Press.

Rocha Menocal, A. (2014). Getting real about politics: From thinking politically to working differently. London: Overseas Development Institute.

Shreyögg, G., \& Kliesch-Eberl, M. (2007). How dynamic can organizational capabilities be? Towards a dual process model of capability dynamization. Strategic Management Journal, 28 (9), 913-33.

Sunningdale Institute. (2007). Take-off or tail-off? An evaluation of the Capability Reviews Programme. London: Sunningdale Institute.

Tranfield, D., Duberley, D., Smith, S., Musson, G., \& Stokes, P. (2000). Organisational learning - It's just routine. Management Decision, 38 (4), 253-60. 